\title{
ABO GENOTYPING OF COMPLETE HYDATIDIFORM MOLES
}

\author{
R.A. FISHER*, P.H. JOHNSON $\$$, S. POVEY $\$$, D.A. HOPKINSON ${ }^{\$}$ AND S.D. LAWLER ${ }^{\dagger}$ \\ * Cancer Research Campaign Laboratories. Department of Medical Oncology and Department of \\ Biochemistry, Charing Cross and Westminster Medical School, St. Dunstan's Road, Hammersmith, \\ London W6 8RP, UK. \\ $\$$ MRC Human Biochemical Genetics Unit, Galton Laboratory (UCL), Wolfson house, 4 Stephenson \\ Way, London NWI $2 \mathrm{HE}, \mathrm{UK}$. \\ ${ }^{\dagger}$ Institute of Cancer Research, Fulham Road, London SW3 6JB, UK.
}

\begin{abstract}
SUMMARY
It has been suggested that the $\mathrm{ABO}$ blood group of a patient and her partner influence the clinical outcome for patients having a pregnancy with a complete hydatidiform mole (CHM). Since CHM lack red blood cells, it has not previously been possible to type CHM serologically and investigate the relationship between the blood group of the CHM and that of the patient. In the present study we have demonstrated the feasibility of using molecular genotyping to determine the $\mathrm{ABO}$ genotype of $\mathrm{CHM}$, the $\mathrm{ABO}$ genotype being consistent with the androgenetic origin of CHM in all cases. In the series of 48 cases of $\mathrm{CHM}$, the requirement for chemotherapy was not significantly different in those patients with a CHM of like blood group compared with those with a CHM of unlike blood group.
\end{abstract}

KEY WORDS Hydatidiform mole ABO blood groups

\section{INTRODUCTION}

Hydatidiform moles (HMs) are usually benign and resolve spontaneously but in some patients treatment, with chemotherapy, is required due to the development of a trophoblastic tumour (Bagshawe et al., 1986). Interest in the ABO blood groups in gestational trophoblastic diseases, which include complete and partial HMs and malignant choriocarcinoma, has concentrated on the $\mathrm{ABO}$ blood groups of the patients and the $\mathrm{ABO}$ mating type of the patients and their partners (Bagshawe et al., 1971; Bagshawe, 1982; Lawler and Fisher, 1987). In a prospective study at the Royal Marsden Hospital (Lawler and Fisher, 1987) it was shown that a patient with a complete HM (CHM) whose partner has the same $\mathrm{ABO}$ blood group was less likely to require treatment for a trophoblastic tumour than a patient with a partner of different $\mathrm{ABO}$ blood group.

CHMs are derived from an androgenetic conceptus and show characteristic trophoblastic proliferation with absence of fetal development. Thus no fetal red blood cells are present and conventional serological typing is not possible. Studies of ABH blood group antigens by immunofluorescence staining has shown that placental trophoblast from five weeks to term does not express A B or H blood group antigens (Szulman, 1972). Thus direct examination of the $\mathrm{ABO}$ blood group of molar tissue is not possible.

Correspondence to: Dr. R.A. Fisher, Cancer Research Campaign Labs., Dept. of Medical Oncology, Charing Cross and Westminster Med. School, St. Dunstan's Rd., Hammersmith, London W6 8RP, UK. 
Cloning and sequencing of the ABO genes (Yamamoto et al., 1990) has opened up the possibility of determining the $\mathrm{ABO}$ genotype of tissue from which DNA is available. The development of a method for detecting ABO blood group polymorphisms of DNA based on the polymerase chain reaction (Ugozzoli and Wallace, 1992; Johnson and Hopkinson, 1992) has enabled us to determine the ABO genotype of CHM, and examine the relationship between the maternal and molar $\mathrm{ABO}$ blood groups, in terms of the subsequent development of a gestational trophoblastic tumour.

\section{MATERIALS AND METHODS}

We have previously carried out a study to examine the genetic origin of HMs in relation to clinical outcome (Lawler et al., 1991). In the later part of the study DNA was prepared from cases of HM. Clinical data collected included serological typing of the ABO blood group of the patient and, where possible, her partner. Cases of CHM, where DNA was available from the HM and the ABO blood group of the patient was known were selected for the present study. These forty nine cases included 41 Caucasian, six Asian and two patients of Chinese origin. The ABO blood group was available for the paternal parent in 38 cases. In two cases where the paternal $\mathrm{ABO}$ blood group was unknown, DNA was available for typing.

Thirty six of the CHM entered in the study resolved spontaneously while in thirteen cases the patient required chemotherapy for persistent trophoblastic disease.

DNA typing of the $49 \mathrm{CHM}$ and two paternal samples were carried out as described (Johnson and Hopkinson, 1992). (Figure 1a). Only a narrow separation was observed between the $\mathrm{O}_{1}$ and $\mathrm{O}_{2}$ alleles and their unequivocal resolution was difficult. Amplification of the same DNA fragment by PCR using the same pair of nucleotide primers with the GC clamp attached to the downstream primer lead to enhanced resolution of the $\mathrm{O}_{1}$ and $\mathrm{O}_{2}$ alleles although their relative positions were reversed (Figure $1 \mathrm{~b}$ ); however under these conditions the resolution of $\mathrm{B}$ from $\mathrm{O}_{2}$ and $\mathrm{A}$ from $\mathrm{O}_{1}$ was lost.

\section{RESULTS}

The ABO genotype was established in 48 of the 49 CHM entered in the study (Table 1) and the two paternal samples. The ethnic origin of non-Caucasian patients is indicated in the table.

In all 39 cases where the $\mathrm{ABO}$ blood group of the father was known the $\mathrm{ABO}$ genotype of the CHM was consistent with an origin by androgenesis. On the basis of previous genetic studies (Lawler et al., 1991) twenty six of the CHM samples were classified as monospermic (homozygous genome) and six as dispermic (heterozygous genome). All of the monospermic CHM were shown to have a homozygous $\mathrm{ABO}$ genotype. Of the six dispermic CHM, 2 were found to be heterozygous and four homozygous for the ABO alleles. A heterozygous ABO genotype was identified in a further 3 of the $16 \mathrm{CHM}$ not previously classified as monospermic of dispermic.

The relationships between the maternal and paternal ABO blood groups in those cases where both parental phenotypes was known are shown in Table 2. Patients were classified as like (A X A, O X O, B X B, AB X AB) or unlike (all other matings) their partner. No significant difference was found between the like and the unlike group in the incidence of gestational trophoblastic tumours $(\mathrm{p}=0.46)$. 


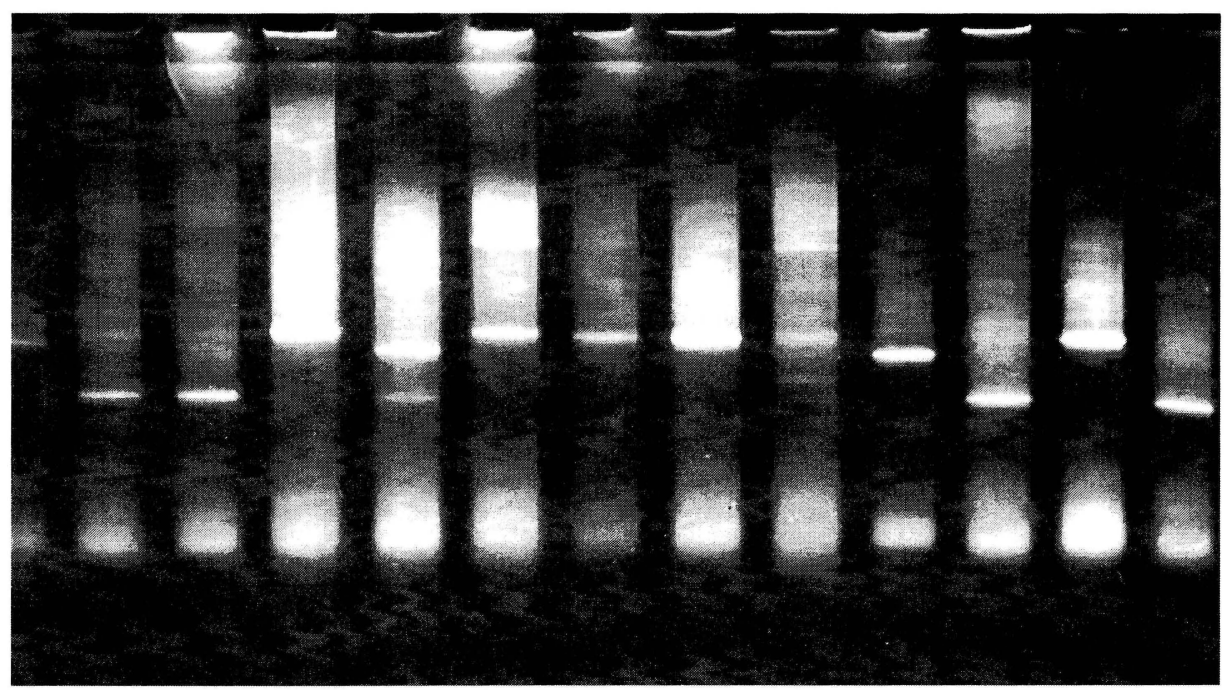

Figure la

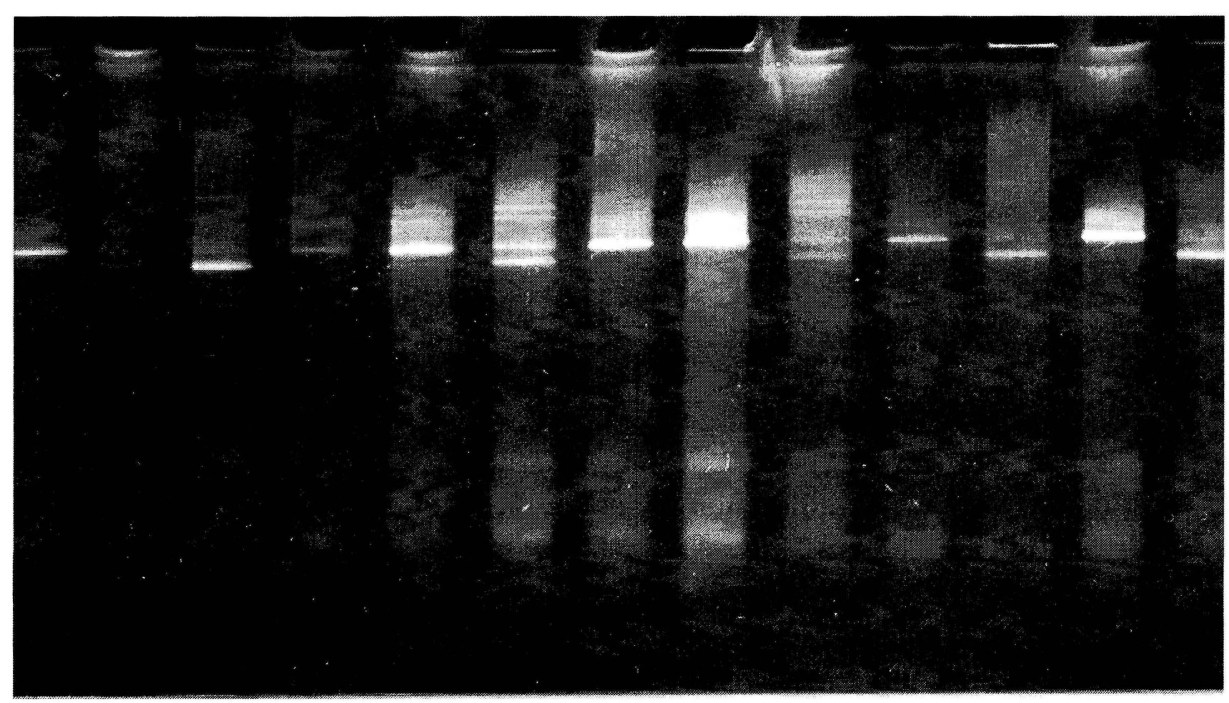

Figure 1b

Figure 1. DGGE analysis of the ABO gene in hydatidiform moles. DNA spanning the O deletion site of the ABO gene was amplified a) as described by Johnson and Hopkinson (1992). In b) the 40 base pair GC clamp sequence was attached to the other primer and the target sequence amplified as before.Tracks $1-4,6-8$, and 10-13 show DNA from hydatidiform moles. $\mathrm{AB}$ and $\mathrm{O}_{1} \mathrm{O}_{2}$ control DNAs were run on tracks 5 and 9. 
Table 1 . The ABO genotypes of 48 complete hydatidiform moles.

\begin{tabular}{l|ccc|ccccccc|c|}
\hline ABO genotypes & $\mathrm{O}_{1} \mathrm{O}_{2}$ & $\mathrm{O}_{1} \mathrm{O}_{1}$ & $\mathrm{O}_{2} \mathrm{O}_{2}$ & $\mathrm{O}_{1} \mathrm{~A}$ & $\mathrm{O}_{2} \mathrm{~A}$ & $\underline{\mathrm{AA}}$ & $\underline{\mathrm{O}_{1} \mathrm{~B}}$ & $\underline{\mathrm{O}_{2} \mathrm{~B}}$ & $\underline{\mathrm{BB}}$ & $\underline{\mathrm{AB}}$ & $\underline{\text { Total }}$ \\
\hline $\begin{array}{l}\text { Treatment } \\
\text { required }\end{array}$ & $\begin{array}{c}\mathrm{c}=1) \\
1\end{array}$ & 7 & 2 & 0 & 0 & 2 & 0 & 0 & 1 & 0 & 13 \\
$\begin{array}{l}\text { Resolved } \\
\text { spontaneously }\end{array}$ & 1 & 10 & 5 & 2 & 0 & 11 & 0 & 1 & 5 & 0 & 35 \\
\hline \begin{tabular}{l} 
Total \\
\hline
\end{tabular} & 2 & 17 & 7 & 2 & 0 & 13 & 0 & 1 & 6 & 0 & 48 \\
\hline
\end{tabular}

\section{a - patient of Asian origin}

c - patient of Chinese origin

The relationships between the maternal and the $\mathrm{CHM} A B O$ blood group are shown in Table 3. Patients were classified as like (A X A, O X O, B X B, AB X AB) or unlike their $\mathrm{CHM}$ and comparisons made between the proportion of patients with spontaneous resolution of their molar pregnancy and those who required treatment for a trophoblastic tumour. No significant difference was found between the need for treatment in the like and unlike groups $(\mathrm{p}=0.57)$.

Because of the unusual origin of $\mathrm{CHM}$ it is not possible to compare the $\mathrm{ABO}$ phenotypes found in the $\mathrm{CHM}$ with those in a normal control population. The frequency of alleles found in the CHM of European origin, $\mathrm{O}_{1}-0 \cdot 39, \mathrm{O}_{2}-0 \cdot 20, \mathrm{~A}-0 \cdot 30$, and $\mathrm{B}$ $0 \cdot 11$ (Table 1) showed a slight excess of $A$ and $B$ alleles when compared with 95 unrelated Europeans (Johnson and Hopkinson, 1992), $\mathrm{O}_{1}-0 \cdot 41, \mathrm{O}_{2}-0 \cdot 27, \mathrm{~A}-0 \cdot 23$, and B - 0.06.

A greater proportion of CHM with an O phenotype (10/26) progressed to a gestational trophoblastic tumour than those with other phenotypes $(3 / 22)(\chi 2$ with Yates correction for small samples $=2.6 ; \mathrm{p}=0.1$ ).

\section{DISCUSSION}

Previous studies have suggested that in patients with a CHM the ABO blood group of the patient and her partner influence the clinical outcome of the HM. Progression of the HM to a trophoblastic tumour has been shown to be more common in patients with blood groups unlike that of their partner (Bagshawe et al., 1971; Bagshawe, 1982; Lawler and Fisher, 1987). Since CHM are androgenetic and their genome is paternally derived this observation is likely to reflect the relationship between the HM and the patient and suggests that patients with HM of unlike blood group may be at greater risk of a trophoblastic tumour.

In the past a full investigation of the role of the $\mathrm{ABO}$ blood group system in gestational trophoblastic disease has been limited because ABO typing of molar or choriocarcinoma 
Table 2. ABO blood groups of patients and their partners.

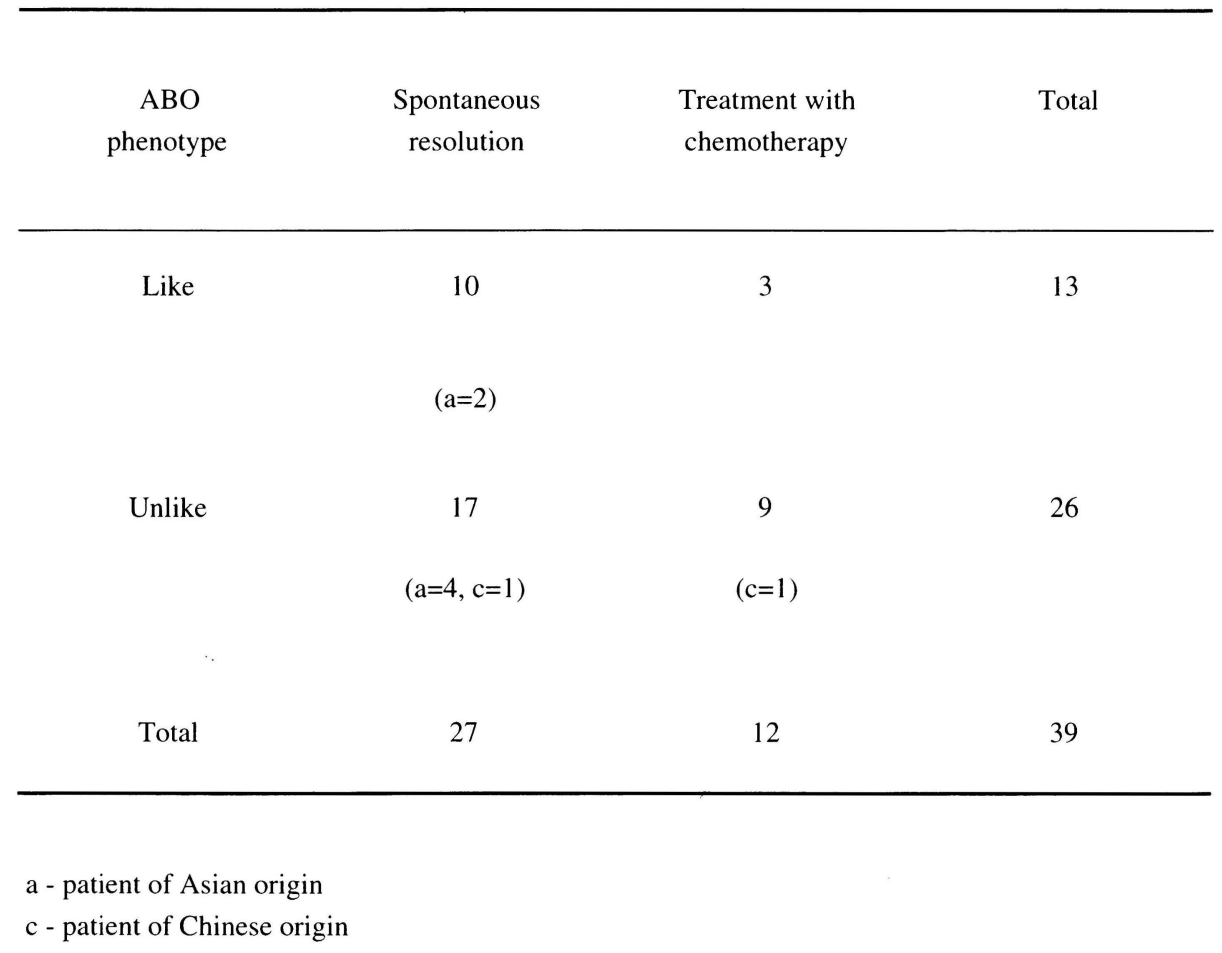

tissue has not been possible. However, the recent development of techniques for ABO genotyping of DNA (Yamamoto et al., 1990; Ugozzoli and Wallace, 1992; Johnson and Hopkinson, 1992) makes it possible to determine the ABO group of tissue where DNA is available. This has enabled us to determine the ABO genotype of a series of HM.

In this particular small series, the significant difference between couples of like or unlike blood groups seen in larger series (Bagshawe et al., 1971; Bagshawe, 1982; Lawler and Fisher, 1987) was not observed. However, any association between the ABO group and the subsequent development of trophoblastic tumours might be expected to be more marked in terms of the relationship between the HM and the patient. We therefore went on to examine the blood group of the patient and the CHM in relation to the outcome of the molar pregnancy.

We have demonstrated the feasibility of determining the $\mathrm{ABO}$ group of $\mathrm{CHM}$ by molecular genotyping and feel confident that the $\mathrm{ABO}$ genotyping of the $\mathrm{CHM}$ is correct. In those cases where the paternal $\mathrm{ABO}$ blood group was known, all the $\mathrm{ABO}$ genotypes of the CHM were consistent with the androgenetic origin of CHMs. Nor were there any examples of a heterozygous $\mathrm{ABO}$ phenotype in cases of $\mathrm{CHM}$ where the diagnosis of monospermic CHM had been made previously (Fisher et al, 1989).

ABO genotyping by the method used in this study allows division of blood group $\mathrm{O}$ into at least two types. Although the biological significance is not known, it does enable identification of heterozygosity in some $\mathrm{CHM}$ with an $\mathrm{O}$ phenotype. Dispermic CHM 
Table 3. ABO blood groups of patients and complete hydatidiform moles.

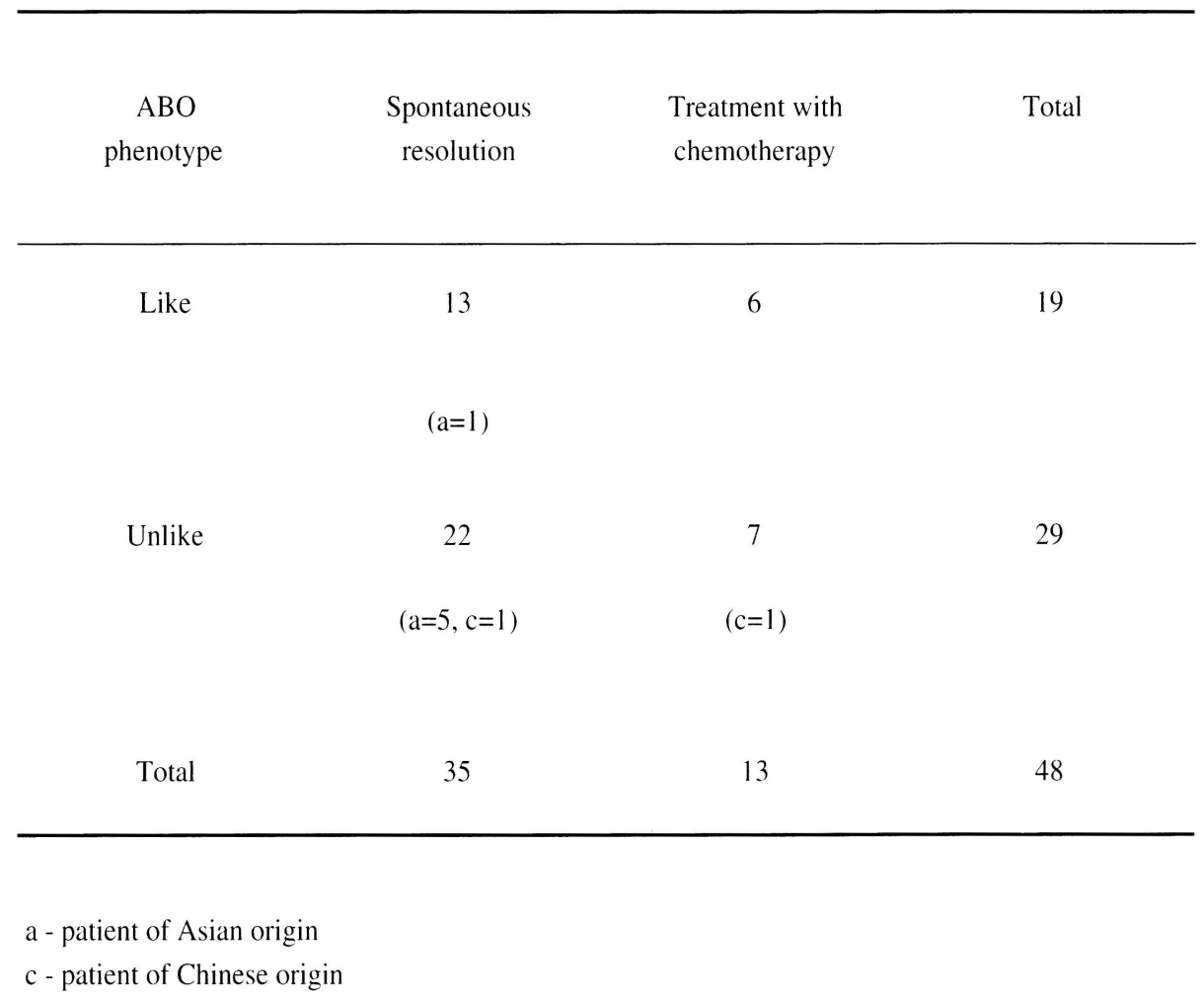

may be homozygous or heterozygous for paternal polymorphisms. Three dispermic CHM were identified, on the basis of ABO genotype, among the $16 \mathrm{CHM}$ in the series not previously classified as monospermic or dispermic. The ABO genotype can therefore be used as an additional marker in the classification of monospermic and dispermic CHM. In this context we also attempted to genotype DNA prepared from formalin-fixed, paraffin-embedded blocks of molar and tumour tissue. Unfortunately good results were not obtained from this source.

To examine the relationship between the patient and HM blood group, the ABO phenotype of the CHM, deduced from the genotype, was compared with the patient's blood group, determined by serological typing. Of the 39 patients of Caucasian origin, 6 of 24 with blood group O, 4 of 13 with blood group A, 1 of 2 with blood group B and the one patient of blood group $\mathrm{AB}$ required treatment for gestational trophoblastic disease. The number of patients were too small to assess the relative significance of different blood groups in the patient.

Comparing the $\mathrm{ABO}$ type of the patients with their HM, no significant difference was found in terms of requirement for chemotherapy between those patients in whom the $\mathrm{CHM}$ and patient were of like blood group and those in whom the CHM and patient were of unlike blood group. CHM, phenotypically unlike the mother showed no greater risk of developing to a trophoblastic tumour. 
In the present study a greater proportion of CHM with an $\mathrm{O}$ phenotype progressed to a gestational trophoblastic tumour than those with other phenotype suggesting that a $\mathrm{CHM}$ with an O blood group phenotype may be a risk factor for the development of trophoblastic disease. This effect appears to be independent of the patient's ABO type. Genotype $\mathrm{OO} \mathrm{HM}$ progressing to a trophoblastic tumour were found in patients with $\mathrm{O}$ phenotype (5/25) and in patients of other phenotypes (5/23). A larger prospective study would be required to determine the relative risk of developing a trophoblastic tumour associated with each genotype. In view of the fact that the $\mathrm{ABH}$ antigens are not expressed on placental tissue (Szalman, 1972) the effect observed is unlikely to be related to expression of the $\mathrm{O}$ phenotype.

Clarification of the effect of the compatibility between patient and conceptus on the risk of development of a trophoblastic tumour would require a large prospective study of the ABO system in parents and CHM based on a molecular genetic diagnosis of CHM and $\mathrm{ABO}$ genotyping. This would enable more detailed analysis of specific blood groups and to consider the ethnic heterogeneity of the patients studied. We have demonstrated that such a study would be feasible and that blood group O in CHM may be a risk factor for the development of trophoblastic tumours after evacuation of the HM.

\section{ACKNOWLEDGEMENTS}

We are grateful to the many obstetricians and gynaecologists who have supplied us with tissue from their patients. We would like to thank the staff of the Trophoblastic Tumour Screening and Treatment Centre for follow up records of the patients. This work was funded by the Medical Research Council, as part of the UK Human Genome Mapping Project, and the Cancer Research Campaign.

\section{REFERENCES}

Bagshawe, K.D., Rawlins, G., Pike, M.C., Lawler, S.D. (1971). ABO blood-groups in trophoblastic neoplasia. Lancet, i, 553-557.

Bagshawe, K.D. (1982). Some facets of trophoblastic neoplasia in man. J. Reprod. Fert. Suppl. 31, 175-179.

Bagshawe, K.D., Dent, J., Webb, J. (1986). Hydatidiform mole in England and Wales 1973-83. Lancet, ii, 673-677.

Fisher, R.A., Povey, S., Jeffreys, A.J., Martin, C.A., Patel, I., Lawler, S.D. (1989). Frequency of heterozygous complete hydatidiform moles, estimated by locus-specific minisatellite and $\mathrm{Y}$ chromosome-specific probes. Hum. Genet., 82, 259-263.

Johnson, P.H., Hopkinson, D.A. (1992). Detection of ABO blood group polymorphism by denaturing gradient gel electrophoresis. Hum. Molec. Genet., 1, 341-344.

Lawler, S.D., Fisher, R.A. (1987). Immunogenicity of hydatidiform moles. Placenta, 8, 195-199. Lawler, S.D., Fisher, R.A., Dent, J. (1991). A prospective study of hydatidiform mole. Am. J. Obstet. Gynec., 164, 1270-1277.

Szulman, A.E. (1972). The A, B, H blood group antigens in human placenta. New Engl. Jnl. Med., 286, 1028-1031.

Ugozolli, L., Wallace, R.B. (1992). Application of an allele-specific polymerase chain reaction to the direct determination of ABO blood group geneotypes. Genomics, 12, 670-674.

Yamamoto, F-i., Clausen, H., White, T., Marken, J., Hakomori, S-i. (1990). Molecular basis of the histo-blood group ABO system. Nature, 345, 229-233. 


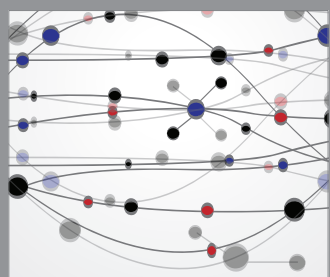

The Scientific World Journal
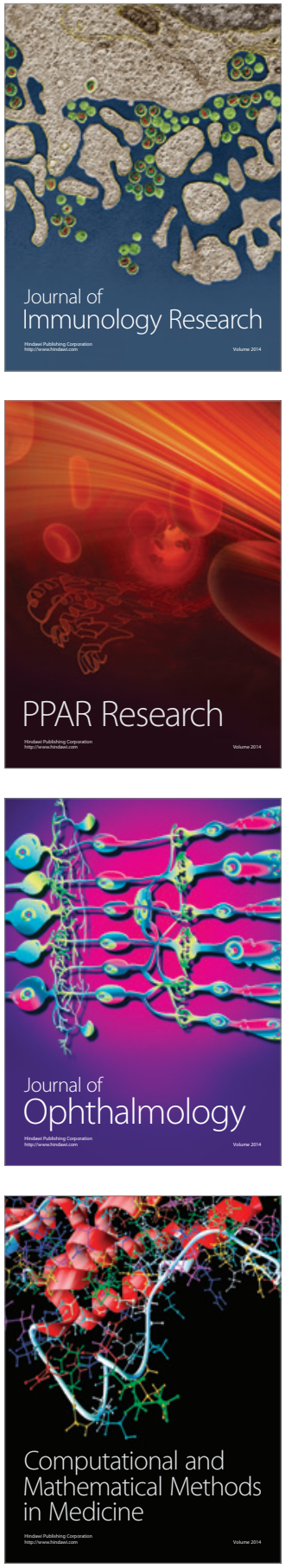

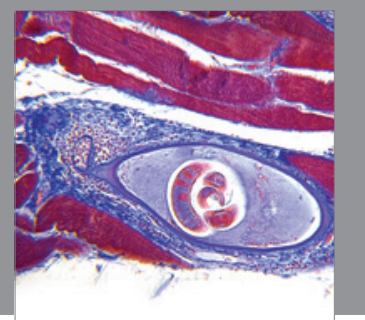

Gastroenterology

Research and Practice
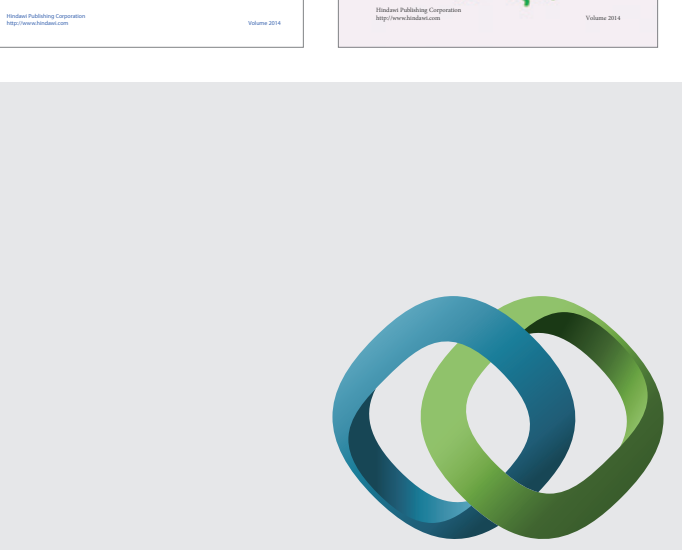

\section{Hindawi}

Submit your manuscripts at

http://www.hindawi.com
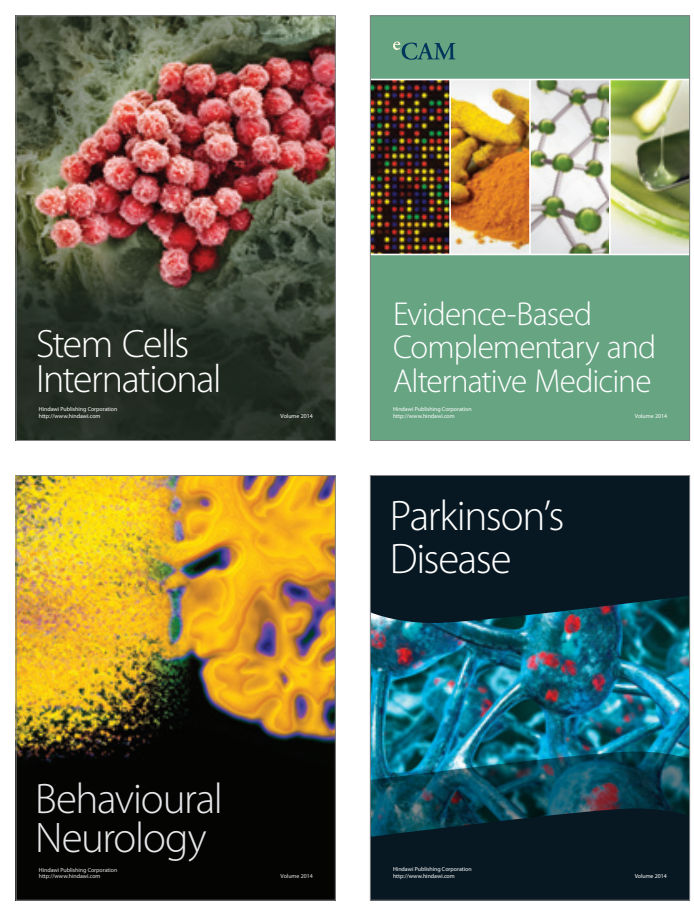

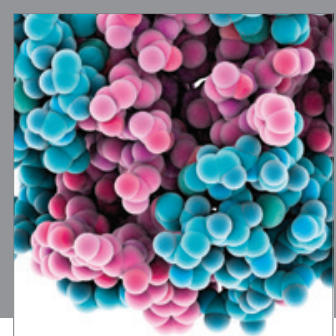

Journal of
Diabetes Research

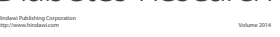

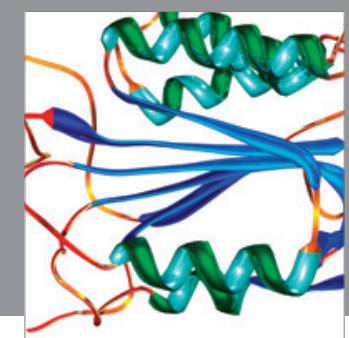

Disease Markers
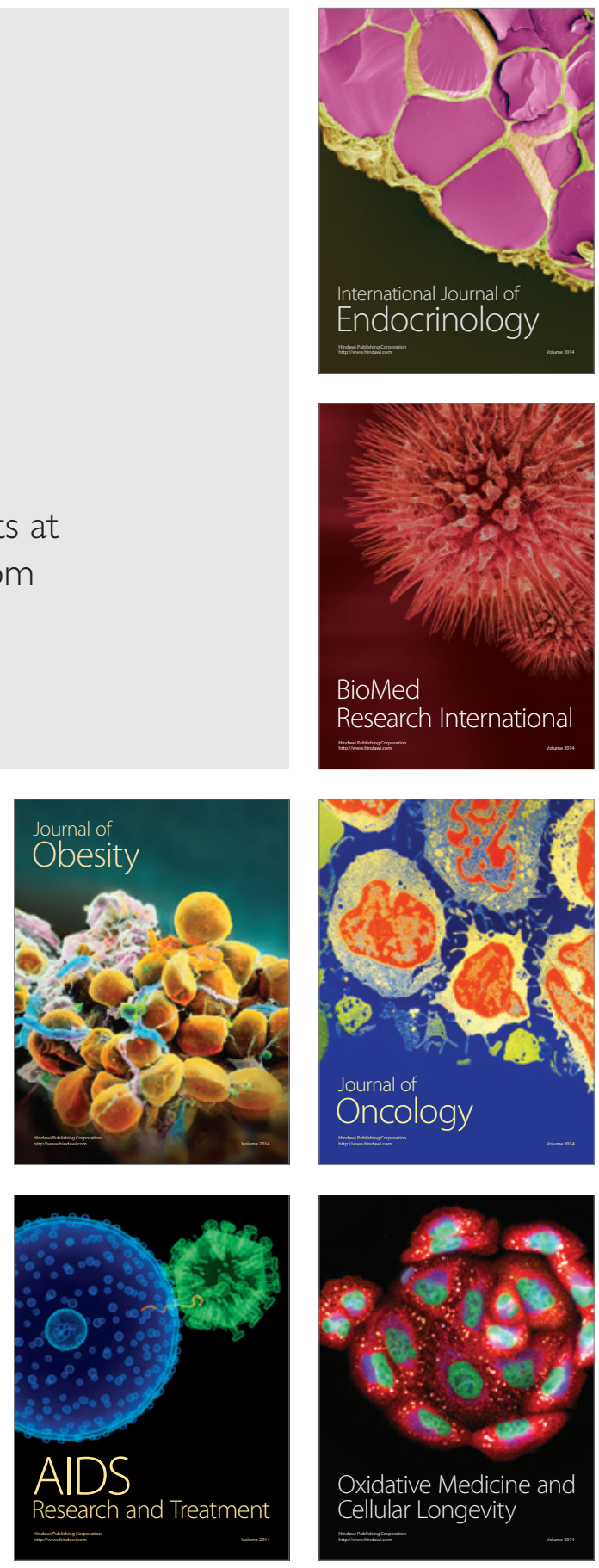